\title{
THE IMPORTANCE OF HIGH INDEX OF SUSPICION AND IMMEDIATE CONTAINMENT OF SUSPECTED COVID-19 CASES IN INSTITUTE OF HIGHER EDUCATION SABAH, MALAYSIA BORNEO
}

Loganathan Salvaraji, Syed Sharizman Syed Abdul Rahim, Mohammad Saffree Jeffree, Azizan Omar, Nicholas Tze Ping Pang, Fatimah Ahmedy, Firdaus Hayati ${ }^{1}$, Yeap Boon Tat, Nelbon Giloi ${ }^{1}$, Sahipudin Saupin, Assikin Muhamad and Syaza Putri Zainudin

Faculty of Medicine \& Health Sciences, Universiti Malaysia Sabah, Kota Kinabalu 88400, Malaysia

Corresponding author: Syed Sharizman Syed Abdul Rahim

Email: syedsharizman@ums.edu.my

\begin{abstract}
Higher education institutions face major challenges in managing the impact of the COVID-19 pandemic. The risk of exposure from the community poses a threat to campus staff and students. This study describes epidemiological characteristics of suspected COVID-19 cases among a public university's students and staff. This is a retrospective review on data collected from the institute's COVID-19 Preparedness and Respond Centre, located at the main campus in Kota Kinabalu, the capital city of Sabah from mid-January to April 2020. Incidence rate was calculated, and epidemiological information retrieved from interviews and relevant documents. The majority of suspected COVID-19 cases were staff (57.1\%) with incidence rates higher among males (IR=40.2/1,000 population) and those working in the frontline (IR=39.6/1,000 population). Suspected COVID-19 cases were mostly related to occupation (37.3\%) and social contacts (27.3\%). Student cases were largely related to household (38.1\%) and during travel (33.3\%). One positive COVID-19 case was reported of out of the 161 suspected cases (0.6\%) in the institution. An operational team must be set up to conduct situational analysis and integrate management with other departments. Suspected COVID-19 cases must be quarantined and monitored on a daily basis. A high index of suspicion and effective containment of suspected cases will prevent spread of the virus among students and staff.
\end{abstract}

Keywords: Suspected COVID-19 Cases, higher learning institution, university, Sabah, Borneo.

\section{INTRODUCTION}

COVID-19 was first detected in Wuhan City, Hubei Province, China and declared as a global pandemic on 11 March 2020. ${ }^{1}$ The source of human transmission is believed to be by consumption or by direct contact with infected animals, causing transmission to healthy persons. ${ }^{2,3}$

Higher education institutions face major challenges in coping with the impact of COVID-19 on teaching and learning activities, research, student mobility, campus culture and many more. ${ }^{4}$ Universiti Malaysia Sabah (UMS), on Borneo island, has a wide network of branch campuses, with some located at districts reporting COVID-19 cases. ${ }^{5}$ Complicating the matter, foreign students study in UMS too, with the majority from Asian countries such as China, Korea and Japan. ${ }^{6}$ There is also collaboration with universities abroad for international conferences, events and meetings for sharing knowledge, research and innovation. ${ }^{5}$ With such potential for Covid-19 spread in mind, the university has implemented several steps in preparedness even since the alert phase to prevent any COVID-19 infections and emergence of clusters. ${ }^{7}$

In China, as of $11^{\text {th }}$ February 2020, around sixtytwo percent of individuals confirmed for COVID19 were drawn from nearly 70,000 suspected cases. The majority of them were from the working age group (87\%), who mobilized freely and reported to have milder symptoms (81\%). Only one percent of suspected cases appear to be without symptoms. ${ }^{8}$ Nevertheless, asymptomatic confirmed cases have a median communicable period of three weeks and develop milder symptoms later. ${ }^{9}$ The screening results of confirmed COVID-19 cases was reported to have an asymptomatic ratio of $41.6 \% \quad(95 \% \mathrm{Cl}$ : $16.7 \%, 66.7 \%) .{ }^{10}$ Therefore, infectivity levels are roughly similar in symptomatic and asymptomatic cases. ${ }^{11}$ Mass testing results in laboratories facing urgent needs for competent staff, supply of reagents and instruments to run test for the samples taken from suspected cases. Malaysia has 43 laboratories to run polymerase chain reaction (PCR) tests, which take a long duration of time for transporting and performing the test. ${ }^{12}$ This was 
evidenced by the Sabah Health Department having approximately 3,000 to 4,000 backlogs of samples from suspected COVID-19 cases during the peak of the Covid-19 pandemic. ${ }^{13}$

In Malaysia, all universities were closed since the Movement Control Order (MCO) was ordered on 18 March 2020 as part of a prevention effort to reduce the transmission of the virus. Teaching and learning activities were continued by using online tools. ${ }^{14}$ However, essential services were needed for students in the hostel and staff working in faculties, university health clinics, hospitals and laboratories. Therefore, health education and promotion to prevent COVID-19 needed to be intensified for better understanding and updates of the situation or restrictions. Public health activities and surveillance systems had to be in place for prompt activation and responses to investigate suspected cases and contacts for screening by operational teams. ${ }^{15}$

Experts believe public health management in contact tracing, monitoring, isolation, quarantine, social distancing and containment can break the transmission circuit and reduce the occurrence of COVID-19 cases. ${ }^{16}$ Government and non-government organizations are implementing and practicing these measures at their facilities and workplace. Hence, this article describes epidemiological characteristics in an institute of higher education in managing suspected COVID-19 cases among students and staff. The study also emphasises the importance of high indexes of suspicion to contain suspected COVID-19 cases, thus hindering the virus from circulating in the institute.

\section{METHODS}

This study was conducted at Universiti Malaysia Sabah, an institute of higher education in Sabah, Malaysia Borneo which was divided into four campuses. These campuses are located at the districts of Kota Kinabalu, Sandakan, Labuan and Kudat. The Kota Kinabalu campus was established as the headquarters, coordinating management and resources, with other campuses covering certain specific courses. This is a retrospective review on operational data collected from the university COVID-19 Preparedness and Response Centre from mid-January to April 2020 during the height of the pandemic. The review utilizes secondary data for epidemiological analysis of suspected COVID-19 cases among students and staff. Suspected COVID-19 was defined as those individuals who are asymptomatic or experience acute respiratory infections such as sudden onset of at least one of shortness of breath, cough or sore throat) with or without fever AND one of the following; i) Travelled to foreign country or other states in Malaysia, ii) Close contact with confirmed case of COVID-19 iii) Attended any event or mass gathering such as conference, meeting, workshop and course.
A mixed method approach was utilised, combining key information interviews, document analysis and secondary data analyses. A line listing was established by the operational team to manage the COVID-19 pandemic, adapting to an institute of higher education setting and environment. The line listing, created via a spreadsheet, comprises several variables including sociodemographic data, occupational data, contact history, source of transmission, clinical presentation, quarantine, monitoring, admission to hospital, discharge from health facilities and death. Occupational details include frontline (healthcare workers, security guards, laboratory technician and student affairs staff) and non-frontline (management staff, technicians, academicians, and cleaners). The type of contacts with patient under investigation (PUI) or confirm COVID-19 cases was classified into the following categories: during work (occupation), travelling purposes (travel), staying together (household) or attended mass gatherings (social). The possible source of transmission could also be imported, whereby the individual had travelled outside Malaysia. For possible local sources of transmission, the suspected COVID-19 case might have been from a red zone, from a known Covid-19 cluster, or sporadic. A red zone was defined as a particular area reporting more than 41 cases of COVID 1917. Clusters were defined as group of individuals who had attended a particular event and had been investigated for COVID-19. Sporadic cases were defined as cases whereby only a single case was present at the area and the epidemiology link was as such indeterminate.

Only designated officers were allowed and were hence responsible to investigate suspected COVID-19 cases and update relevant information into the line listing. Investigators have the authority and permission to converge and generate data belonging to the suspected COVID19 cases. The relevant operational team then receives information regarding staff and students who are suspected to have COVID-19 from various sources (Figure 1). This includes staff and residential students who are required to selfdeclare travel history from abroad or other Malaysian states and referred to campus health clinics as indicated. Non-residents of UMS and visitors are screened for any symptoms of COVID19 at the entry point. Furthermore, management, human resource and student welfare teams monitor students and staff closely and refer them to health clinics if suspected for COVID-19. Besides that, the nearest district health office or hospitals have been briefed to inform the operational room if any students or staff are admitted or investigated for COVID-19.

Data from the line listing was analysed using IBM SPSS statistical software package, version 26.0. The denominators were collected from the management office, representing the finding in Incidence Rate (IR) expected for the age. The 
variable of interest was extracted from the data, analysed and interpreted into a table. The date of notification of suspected COVID-19 cases were analysed and compared to locally reported cases of COVID-19. Epidemiological case studies on positive COVID-19 cases were described according to timeline, contact tracing, monitoring and quarantine.

Approval to conduct the study was obtained from the Medical Research Ethics Committee, Faculty of Medicine and Health Science, University Malaysia Sabah.

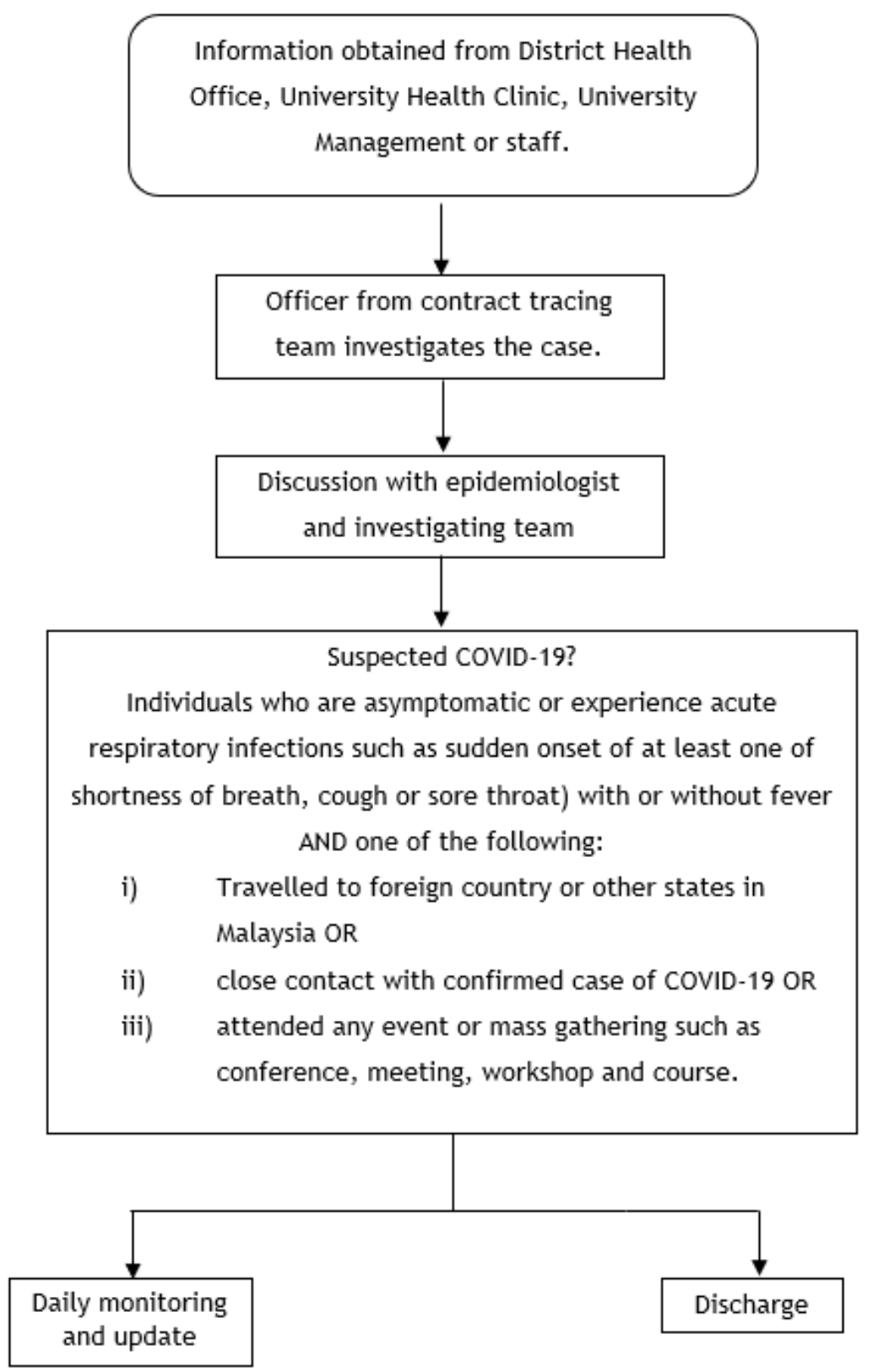

Figure 1 Flow chart for investigating suspected case for COVID 19.

RESULTS

A total of 161 suspected COVID-19 cases were reported, with an incidence rate of 9.6 per 1,000 population. Staff accounted for the majority of the cases $(57.1 \%)$. The incidence rate among male staff (IR=40.2/1,000 population) was higher compared to female staff (IR=19.3/1,000 population) (Table 1). The incidence between gender was similar among students (IR student male=5.9/1,000 population; IR student female $=4.6 / 1,000$ population). Frontline staff (IR=39.6/1,000 population) have a higher incidence rate compared to non-frontline staff (Non-frontline staff IR=28.1/1,000 population; Students $I R=5.0 / 1,000$ population). 
Table 1: Incidence rate for suspected COVID-19 cases at the institute of higher education in Sabah, Malaysia Borneo

Variable

Staff

Students

Total

\begin{tabular}{|c|c|c|c|c|c|c|c|c|c|}
\hline & & & \\
\hline & No. Case & Total Staff & *IR & No. Case & Total & *IR & No. Case & Total Staff and Student & *IR \\
\hline \multicolumn{10}{|l|}{$\begin{array}{l}\text { Total }(n=161) \\
\text { Gender }\end{array}$} \\
\hline Male & 65 & 1618 & 40.2 & 26 & 4372 & 5.9 & 91 & 5990 & 15.2 \\
\hline Female & 27 & 1401 & 19.3 & 43 & 9371 & 4.6 & 70 & 10772 & 6.5 \\
\hline Total & 92 & 3019 & 30.5 & 69 & 13743 & 5.0 & 161 & 16762 & 9.6 \\
\hline Median Age (IQR) & & $39(14)$ & & & $23(3)$ & & $30(18)$ & & \\
\hline \multicolumn{10}{|l|}{ Job Position } \\
\hline Frontline & 25 & 632 & 39.6 & 0 & 20 & 0 & 25 & 632 & 39.6 \\
\hline Non-frontline & 67 & 2387 & 28.1 & 69 & 13743 & 5.0 & 136 & 16130 & 8.4 \\
\hline \multicolumn{10}{|c|}{ Kota Kinabalu $(n=102)$} \\
\hline \multicolumn{10}{|c|}{ Gender } \\
\hline Male & 56 & 1389 & 40.3 & 6 & 3720 & 1.6 & 62 & 5109 & 12.1 \\
\hline Female & 25 & 1233 & 20.2 & 15 & 7968 & 1.9 & 40 & 9201 & 4.3 \\
\hline Median Age (IQR) & & $40(13)$ & & & $23(2)$ & & & $37(16)$ & \\
\hline \multicolumn{10}{|l|}{ Job Position } \\
\hline Frontline & 24 & 577 & 41.6 & 0 & 20 & 0 & 24 & 577 & 41.6 \\
\hline Non- frontline & 57 & 2045 & 27.9 & 21 & 11688 & 1.8 & 78 & 13733 & 5.6 \\
\hline \multicolumn{10}{|l|}{ Sandakan $(n=56)$} \\
\hline \multicolumn{10}{|l|}{ Gender } \\
\hline Male & 6 & 83 & 72.3 & 20 & 137 & 146.0 & 26 & 220 & 118.2 \\
\hline Female & 2 & 45 & 44.4 & 28 & 212 & 132.0 & 30 & 257 & 116.7 \\
\hline Median Age (IQR) & & $30(26)$ & & & $22(3)$ & & & $22(3)$ & \\
\hline \multicolumn{10}{|l|}{ Job Position } \\
\hline Frontline & 0 & 21 & 0 & 0 & 0 & 0 & 0 & 21 & 0 \\
\hline Non-frontline & 8 & 107 & 74.8 & 48 & 349 & 137.5 & 56 & 456 & 122.8 \\
\hline \multicolumn{10}{|l|}{ Labuan $(n=3)$} \\
\hline \multicolumn{10}{|l|}{ Gender } \\
\hline Male & 3 & 140 & 21.4 & 0 & 515 & 0 & 3 & 655 & 4.6 \\
\hline Female & 0 & 121 & 0 & 0 & 1191 & 0 & 0 & 1312 & 0 \\
\hline Median Age (IQR) & & $47(16)$ & & & & & & $47(16)$ & \\
\hline \multicolumn{10}{|l|}{ Job Position } \\
\hline Frontline & 1 & 26 & 38.5 & 0 & 0 & 0 & 1 & 26 & 38.5 \\
\hline Non-frontline & 2 & 235 & 8.5 & 0 & 1706 & 0 & 2 & 1941 & 1.0 \\
\hline \multicolumn{10}{|l|}{ Kudat $(n=0)$} \\
\hline \multicolumn{10}{|l|}{$\begin{array}{l}\text { Wuad }(n=U) \\
\text { Gender }\end{array}$} \\
\hline Male & 0 & 6 & 0 & 0 & 0 & 0 & 0 & 6 & 0 \\
\hline Female & 0 & 2 & 0 & 0 & 0 & 0 & 0 & 2 & 0 \\
\hline Median Age (IQR) & & - & & & - & & & - & \\
\hline \multicolumn{10}{|l|}{ Job Position } \\
\hline Frontline & 0 & 8 & 0 & 0 & 0 & 0 & 0 & 8 & 0 \\
\hline Non-frontline & 0 & 0 & 0 & 0 & 0 & 0 & 0 & 0 & 0 \\
\hline
\end{tabular}


Malaysian Journal of Public Health Medicine 2020, Vol. 20 (2): 74-83

Table 2 Epidemiology characteristic for suspected COVID-19 cases at institute of higher education Sabah, Malaysia Borneo

\begin{tabular}{|c|c|c|c|c|c|c|c|c|c|}
\hline \multirow[t]{2}{*}{ Variable } & \multicolumn{3}{|c|}{ Staff } & \multicolumn{3}{|c|}{ Student } & \multicolumn{3}{|c|}{ Total (Staff \& Student) } \\
\hline & No. Case & Total Staff & $\%$ & No. Case & Total Students & $\%$ & No. Case & Total Case & $\%$ \\
\hline \multicolumn{10}{|l|}{ otal $(n=161)$} \\
\hline *Occup. & 55 & 92 & $59.8 \%$ & 5 & 69 & $7.2 \%$ & 60 & 161 & $37.3 \%$ \\
\hline Social & 16 & 92 & $17.4 \%$ & 28 & 69 & $40.6 \%$ & 44 & 161 & $27.3 \%$ \\
\hline Travel & 14 & 92 & $15.2 \%$ & 11 & 69 & $15.9 \%$ & 25 & 161 & $15.5 \%$ \\
\hline Household & 7 & 92 & $7.6 \%$ & 25 & 69 & $36.2 \%$ & 32 & 161 & $19.9 \%$ \\
\hline \multicolumn{10}{|l|}{ ource of } \\
\hline Import & 10 & 92 & $10.9 \%$ & 2 & 69 & $2.9 \%$ & 12 & 161 & $7.5 \%$ \\
\hline \multicolumn{10}{|l|}{ Local } \\
\hline Red & 2 & 92 & $2.2 \%$ & 6 & 69 & $8.7 \%$ & 8 & 161 & $5.0 \%$ \\
\hline Cluster & 78 & 92 & $84.8 \%$ & 57 & 69 & $82.6 \%$ & 135 & 161 & $83.9 \%$ \\
\hline Sporadic & 2 & 92 & $2.2 \%$ & 4 & 69 & $5.8 \%$ & 6 & 161 & $3.7 \%$ \\
\hline \multicolumn{10}{|l|}{ ymptoms } \\
\hline Yes & 10 & 92 & $10.9 \%$ & 16 & 69 & $23.2 \%$ & 26 & 161 & $16.1 \%$ \\
\hline No & 82 & 92 & $89.1 \%$ & 53 & 69 & $76.8 \%$ & 135 & 161 & $83.9 \%$ \\
\hline \multirow{2}{*}{\multicolumn{10}{|c|}{ Kota Kinabalu $(n=102)$}} \\
\hline & & & & & & & & & \\
\hline *Occup. & 55 & 81 & $67.9 \%$ & 5 & 21 & $23.8 \%$ & 60 & 102 & $58.8 \%$ \\
\hline Social & 12 & 81 & $14.8 \%$ & 1 & 21 & $4.8 \%$ & 13 & 102 & $12.7 \%$ \\
\hline Travel & 10 & 81 & $12.3 \%$ & 7 & 21 & $33.3 \%$ & 17 & 102 & $16.7 \%$ \\
\hline Household & 4 & 81 & $4.9 \%$ & 8 & 21 & $38.1 \%$ & 12 & 102 & $11.8 \%$ \\
\hline \multicolumn{10}{|l|}{ ource of } \\
\hline Import & 9 & 81 & $11.1 \%$ & 2 & 21 & $9.5 \%$ & 11 & 102 & $10.8 \%$ \\
\hline \multicolumn{10}{|l|}{ Local } \\
\hline Red & 1 & 81 & $1.2 \%$ & 6 & 21 & $28.6 \%$ & 7 & 102 & $6.9 \%$ \\
\hline Cluster & 71 & 81 & $87.7 \%$ & 13 & 21 & $61.9 \%$ & 84 & 102 & $82.3 \%$ \\
\hline Sporadic & 0 & 81 & $0 \%$ & 0 & 21 & $0 \%$ & 0 & 102 & $0 \%$ \\
\hline \multicolumn{10}{|l|}{ ymptoms } \\
\hline Yes & 8 & 81 & $9.9 \%$ & 5 & 21 & $23.8 \%$ & 13 & 102 & $12.7 \%$ \\
\hline No & 73 & 81 & $90.1 \%$ & 16 & 21 & $76.2 \%$ & 89 & 102 & $87.3 \%$ \\
\hline \multicolumn{10}{|c|}{$\begin{array}{l}\text { andakan }(n=56) \\
\text { ype of }\end{array}$} \\
\hline \multicolumn{10}{|c|}{ ype of } \\
\hline *Occup. & 0 & 8 & $0 \%$ & 0 & 48 & $0 \%$ & 0 & 56 & $0 \%$ \\
\hline Social & 1 & 8 & $12.5 \%$ & 27 & 48 & $56.3 \%$ & 28 & 56 & $50.0 \%$ \\
\hline Travel & 4 & 8 & $50.0 \%$ & 4 & 48 & $8.3 \%$ & 8 & 56 & $14.3 \%$ \\
\hline Household & 3 & 8 & $37.5 \%$ & 17 & 48 & $35.4 \%$ & 20 & 56 & $35.7 \%$ \\
\hline \multicolumn{10}{|l|}{ ource of } \\
\hline Import & 1 & 8 & $12.5 \%$ & 0 & 48 & $0 \%$ & 1 & 56 & $1.8 \%$ \\
\hline \multicolumn{10}{|l|}{ Local } \\
\hline Red & 1 & 8 & $12.5 \%$ & 0 & 48 & $0 \%$ & 1 & 56 & $1.8 \%$ \\
\hline
\end{tabular}




\begin{tabular}{|c|c|c|c|c|c|c|c|c|c|}
\hline $\begin{array}{l}\text { Cluster } \\
\text { Sporadic }\end{array}$ & $\begin{array}{l}4 \\
2 \\
\end{array}$ & $\begin{array}{l}8 \\
8 \\
\end{array}$ & $\begin{array}{l}50.0 \% \\
25.0 \% \\
\end{array}$ & $\begin{array}{c}44 \\
4 \\
\end{array}$ & $\begin{array}{l}48 \\
48 \\
\end{array}$ & $\begin{array}{l}91.7 \% \\
8.3 \% \\
\end{array}$ & $\begin{array}{c}48 \\
6 \\
\end{array}$ & $\begin{array}{l}56 \\
56 \\
\end{array}$ & $\begin{array}{l}85.7 \% \\
10.7 \% \\
\end{array}$ \\
\hline \multicolumn{10}{|l|}{ Symptoms } \\
\hline Yes & 1 & 8 & $12.5 \%$ & 11 & 48 & $22.9 \%$ & 12 & 56 & $21.4 \%$ \\
\hline No & 7 & 8 & $87.5 \%$ & 37 & 48 & $77.1 \%$ & 44 & 56 & $78.6 \%$ \\
\hline \multicolumn{10}{|l|}{ Labuan $(n=3)$} \\
\hline \multicolumn{10}{|l|}{ Type of } \\
\hline *Occup. & 0 & 3 & $0 \%$ & 0 & 0 & $0 \%$ & 0 & 3 & $0 \%$ \\
\hline Social & 3 & 3 & $100 \%$ & 0 & 0 & $0 \%$ & 3 & 3 & $100 \%$ \\
\hline Travel & 0 & 3 & $0 \%$ & 0 & 0 & $0 \%$ & 0 & 3 & $0 \%$ \\
\hline Household & 0 & 0 & $0 \%$ & $0 \%$ & 0 & $0 \%$ & 0 & 0 & $0 \%$ \\
\hline \multicolumn{10}{|l|}{ Source of } \\
\hline Import & 0 & 3 & $0 \%$ & 0 & 3 & $0 \%$ & 0 & 3 & $0 \%$ \\
\hline \multicolumn{10}{|l|}{ Local } \\
\hline Red & 0 & 3 & $0 \%$ & 0 & 3 & $0 \%$ & 0 & 3 & $0 \%$ \\
\hline Cluster & 3 & 3 & $100 \%$ & 0 & 3 & $0 \%$ & 3 & 3 & $100 \%$ \\
\hline Sporadic & 0 & 3 & $0 \%$ & 0 & 3 & $0 \%$ & 0 & 3 & $0 \%$ \\
\hline \multicolumn{10}{|l|}{ Symptoms } \\
\hline Yes & 1 & 3 & $33.3 \%$ & 0 & 3 & $0 \%$ & 1 & 3 & $33.3 \%$ \\
\hline No & 2 & 3 & $66.7 \%$ & 0 & 3 & $0 \%$ & 2 & 3 & $66.7 \%$ \\
\hline \multicolumn{10}{|l|}{ Kudat $(n=0)$} \\
\hline \multicolumn{10}{|l|}{ Type of } \\
\hline *Occup. & 0 & 0 & $0 \%$ & 0 & 0 & $0 \%$ & 0 & 0 & $0 \%$ \\
\hline Social & 0 & 0 & $0 \%$ & 0 & 0 & $0 \%$ & 0 & 0 & $0 \%$ \\
\hline Travel & 0 & 0 & $0 \%$ & 0 & 0 & $0 \%$ & 0 & 0 & $0 \%$ \\
\hline Household & 0 & 0 & $0 \%$ & 0 & 0 & $0 \%$ & 0 & 0 & $0 \%$ \\
\hline \multicolumn{10}{|l|}{ Source of } \\
\hline Import & 0 & 0 & $0 \%$ & 0 & 0 & $0 \%$ & 0 & 0 & $0 \%$ \\
\hline \multicolumn{10}{|l|}{ Local } \\
\hline Red & 0 & 0 & $0 \%$ & 0 & 0 & $0 \%$ & 0 & 0 & $0 \%$ \\
\hline Cluster & 0 & 0 & $0 \%$ & 0 & 0 & $0 \%$ & 0 & 0 & $0 \%$ \\
\hline Sporadic & 0 & 0 & $0 \%$ & 0 & 0 & $0 \%$ & 0 & 0 & $0 \%$ \\
\hline \multicolumn{10}{|l|}{ Symptoms } \\
\hline Yes & 0 & 0 & $0 \%$ & 0 & 0 & $0 \%$ & 0 & 0 & $0 \%$ \\
\hline No & 0 & 0 & $0 \%$ & 0 & 0 & $0 \%$ & 0 & 0 & $0 \%$ \\
\hline
\end{tabular}

${ }^{*}$ Occup. = Occupation 
The majority of contact among suspected COVID19 cases were related to occupational (37.3\%) and social $(27.3 \%)$ contact (Table 2 ). However, this also varies according to campus. In Kota Kinabalu campus, students' contact was largely from household (38.1\%) and travelling (33.3\%). Meanwhile, contacts for staff in Sandakan were linked to travelling (50.0\%) and household (37.5\%). Most exposure was from clusters (83.9\%), with the remaining cases being from foreign import $(7.5 \%)$ and red zone travel $(8.7 \%)$. During initial screening, $83.9 \%$ of the suspected cases appeared to be asymptomatic.

The preparedness and response centre were activated in January once WHO alerted the world regarding COVID-19. Thereafter, the first suspected COVID-19 case in the institute was reported on 13 February 2020 (Figure 2). Prompt action by the institute allowed the situation to be brought under control before the movement control order (MCO) was announced. Even as COVID-19 cases were continuously notified in Sabah, there were no more suspected COVID-19 cases reported among students within the campus.

Since about $80 \%$ of COVID-19 cases appear to be asymptomatic $^{18}$, the Covid-19 preparedness team maintained a high index of suspicion and monitored suspected COVID-19 cases for any clinical signs. They were also quarantined for fourteen days as per protocol. The operational team would call the suspected cases daily to check for any signs and the compliance to quarantine advice. From January until April, the institution only reported one (1) positive COVID19 case of out of the 161 suspected cases (0.6\%). This was a staff who came back from the United Kingdom in mid-March 2020. The case was ordered for immediate home quarantine and the operational team monitored symptoms daily. The case developed very mild symptoms after the third day of home quarantine and was promptly referred to the nearest health clinic for a COVID19 test. The result came back as positive and the case was immediately admitted for isolation and treatment. Contact tracing and containment were commenced immediately.

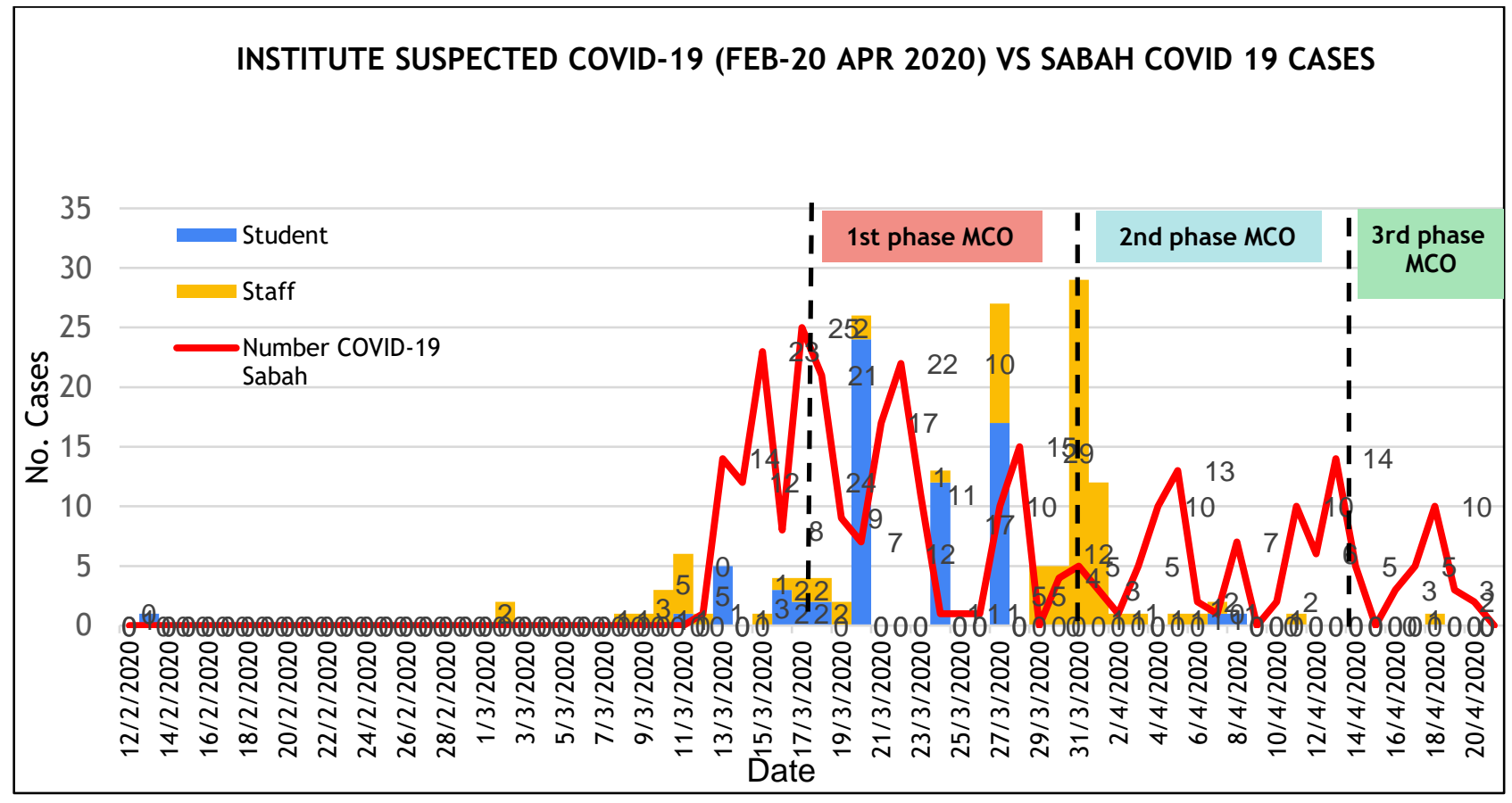

Figure 2: Date of notification of suspected cases of COVID-19 in institute of higher education and COVID-19 cases in Sabah.

\section{DISCUSSION}

Though the early literature showed COVID-19 did not have any association with gender, nevertheless, there are discrepancies in the outcome of the disease in other studies ${ }^{19}$. Lifestyle factors such as smoking and alcohol meant that mortality rates were reported to be more prominent among males ${ }^{20}$. This study revealed an anomaly compared to the literature where most suspected COVID-19 were males $(\mathrm{I}=15 / 1,000$ population). Although the proportion of female students registered in the institute was much higher, the incidence rate was higher in males (IR=6/1,000 population). The median age of the persons under investigation who were students was 23 years old, whereas the median age of staff was 39 years old). The overall median age of the suspected cases was younger (median $=30$ years old) compared to total reported COVID-19 cases, as the CDC China reported that COVID-19 cases were diagnosed between age 30 79 years old $(87 \%)^{8}$. Concurrently, older groups are more prone to develop more severe complications and had higher mortality rates ${ }^{21}$. Almost thirty percent (30\%) of elderly people were 
admitted into hospitals, and case fatality rate of $5 \%-10 \%$ were reported between $65-84$ year's old ${ }^{22}$.

This study concurred with existing literature demonstrating high susceptibility of contracting Covid-19 when front liners are in contact with suspected $\operatorname{cases}^{23}$, with another study in Wuhan highlighted sixty three percent (63\%) of COVID-19 cases are healthcare workers ${ }^{8}$. Other front liners include service industry workers; on the Diamond Princess cruise ship, 20 crew members tested positive for COVID-1924. However, the literature overwhelmingly reveals that the COVID-19 outbreak can be controlled within three months with effective contact tracing and isolation. A major outbreak can be controlled with more than $70 \%$ coverage of contact tracing for reproduction number $\left(R_{0}\right) 2.5$ and more than $90 \%$ coverage of contact tracing for $\mathrm{R}_{0} 3.5^{25}$.

Almost $80 \%$ of suspected cases are linked to clusters in Malaysia such as religious gathering and healthcare clusters, corresponding to the findings in this study within the institution. This thus warranted a high index of suspicion for the operational team to monitor staff and students who are symptomatic closely. Hence, one of the suspected COVID-19 case developed symptoms at day three of home quarantine and was promptly referred to a local health clinic, resulting in the institution's only positive Covid-19 case being proactively and prophylactically detected. Home quarantines are also paramount as 70 to $80 \%$ of cases appear to be asymptomatic, with a COVID19 outbreak on a cruise ship reporting $50 \%$ of cases were asymptomatic, presenting with symptoms later $^{26}$

As the institution, just like the rest of the world in the alert and early containment phase, understandably had insufficient information about COVID-19, the institute had to make preparations using commonplace and time-tested basic public health prevention measures to management the pandemic, as it was a new challenge to all. Coordinating and identifying the relevant faculty and department roles was challenging. This is because new standard operational procedure needed to be established to take care of students especially those who were staying in campus

Nevertheless, even before MCO, the institute had already been put on alert phase, and the operational team worked vigilantly to control and prevent any contact between campus residents and outsiders to reduce the risk of transmission. ${ }^{7}$ Individual with high risk criteria such as fever, symptoms and travelling history were barred from entering the institute. Prevention measures were forwarded to all faculties in order to ensure social distancing was practised and disinfection steps were conducted at their premise. The situation was brought under control and no more suspected COVID-19 cases reported among those students in the campus. Also, ultra-brief psychological interventions were deployed as well to deal with the risk of Covid-19 in students ${ }^{27,28}$, and new tools were validated in order to more accurately measure the fear of Covid-19 amongst students and staff alike ${ }^{29}$.

In future studies, case reports of positive COVID19 cases in higher education institutes can be shared to highlight vital points of possible transmission risks for SARS-CoV-2. Hence, control and prevention measures can be improved at vulnerable locations including lecture halls, conference venues, workshops, libraries, information centres, entry points and locations for practical sessions. Institutes also can share their practices in coordinating and managing students staying in hostel according to standard operational procedures to hinder the spread of SARS-CoV-2.

\section{CONCLUSION}

Higher education institutions face major challenge, with the impact of COVID-19 on teaching and learning, research, student and staff mobility, campus culture, traveling, lectures and conferences. Nevertheless, during the COVID-19 pandemic, an operational team must be set up to control and prevent spread of SARS-CoV-2 virus in the institute. Case investigation must be complete in order to establish epidemiological links and perform extensive contact tracing. Since most COVID-19 cases are asymptomatic, suspected COVID-19 cases need to be quarantined and monitored on a daily basis. High index suspicion of individuals and effective containment of suspected cases will successfully prevent spreading of the virus among students and staff.

\section{ACKNOWLEDGEMENT}

We expressed our gratitude to the support from the top management, front liners, lecturers and students in Universiti Malaysia Sabah for their support.

\section{CONFLICTS OF INTEREST}

The authors declare that they have no competing financial interest. This is a self-funded research

\section{REFERENCES}

1. David.J.C. Coronavirus Disease 2019 (COVID-19): Practice Essentials, Background, Route of Transmission.

2. Yang Z. et al. More Evidence Suggests Pangolins May Have Passed Coronavirus From Bats to Humans.

3. Malaysia MOH. COVID-19 (Guidelines).

4. EAIE. Coping with COVID-19: International higher education in Europe I EAIE. 
5. UMS. Universiti Malaysia Sabah. Official Web Portal. 2020.

6. Peter.0. 102 foreign students among UMS intake | Daily Express Online - Sabah's Leading News Portal.

7. Mukhsam MH, Jeffree MS, Pang NTP, et al. A University-Wide Preparedness Effort in the Alert Phase of COVID-19 Incorporating Community Mental Health and Task-Shifting Strategies: Experience from a Bornean Institute of Higher Learning. Am J Trop Med Hyg. July 2020:tpmd200458. doi:10.4269/ajtmh.20-0458

8. Wu Z, McGoogan JM. Characteristics of and Important Lessons from the Coronavirus Disease 2019 (COVID-19) Outbreak in China: Summary of a Report of 72314 Cases from the Chinese Center for Disease Control and Prevention. JAMA - J Am Med Assoc. 2020;323(13):1239-1242.

doi:10.1001/jama.2020.2648

9. Management of Patients with Confirmed 2019-nCoV | CDC.

10. Nishiura H, Kobayashi T, Miyama $\mathrm{T}$, et al. Estimation of the asymptomatic ratio of novel coronavirus infections (COVID-19). Int J Infect Dis. 2020;94:154-155. doi:10.1016/j.ijid.2020.03.020

11. Maclntyre CR. Global spread of COVID-19 and pandemic potential. Glob Biosecurity. 2020;1(3). doi:10.31646/gbio.55

12. Zainul.E. Malaysia to boost Covid-19 testing capacity with rapid test kits from South Korea | The Edge Markets.

13. Vanar.M. Sabah gets much-needed Covid-19 test kits, medical supplies flown in I The Star Online.

14. Tang.A. Malaysia announces movement control order after spike in Covid-19 cases (updated) | The Star Online.

15. Keeling MJ, Hollingsworth TD, Read JM. Efficacy of contact tracing for the containment of the 2019 novel coronavirus (COVID-19). J Epidemiol Community Health. June 2020. doi:10.1136/jech-2020214051

16. Wilder-Smith A, Freedman DO. Isolation, quarantine, social distancing and community containment: pivotal role for old-style public health measures in the novel coronavirus (2019-nCoV) outbreak. J Travel Med. 2020;27(2). doi:10.1093/jtm/taaa020

17. Kenneth.T. 20 districts are still under red zone category | The Star.

18. Day M. Covid-19: four fifths of cases are asymptomatic, China figures indicate. BMJ. 2020;369:m1375. doi:10.1136/bmj.m1375

19. Zhonghua Liu Xing Bing Xue Za Zhi. [The epidemiological characteristics of an outbreak of 2019 novel coronavirus diseases (COVID-19) in China]. - PubMed - NCBI.

20. Wenham C, Smith J, Morgan R. COVID-19: the gendered impacts of the outbreak. Lancet. 2020;395(10227):846-848. doi:10.1016/S0140-6736(20)30526-2

21. Heymann DL, Shindo N. COVID-19: what is next for public health? Lancet. 2020;395. doi:10.1016/S0140-6736(20)30374-3

22. CDC. Severe Outcomes Among Patients with Coronavirus Disease 2019 (COVID-19) - United States, February 12-March 16, 2020.; 2020.

23. Abdullah JM, Wan Ismail WFN, Mohamad I, et al. A Critical Appraisal of COVID-19 in Malaysia and Beyond. Malaysian J Med Sci. 2020;27(2):1-9.

doi:10.21315/mjms2020.27.2.1

24. Sim MR. The COVID-19 pandemic: major risks to healthcare and other workers on the front line. Occup Environ Med. 2020;77(5):oemed-2020-106567. doi:10.1136/oemed-2020-106567

25. Hellewell J, Abbott S, Gimma A, et al. Feasibility of controlling COVID-19 outbreaks by isolation of cases and contacts. Lancet Glob Heal. 2020;8(4):e488-e496. doi:10.1016/S2214$109 \times(20) 30074-7$

26. Nishiura H, Kobayashi T, Miyama T, et al. Estimation of the asymptomatic ratio of novel coronavirus (2019-nCoV) infections among passengers on evacuation flights. medRxiv.

February 2020:2020.02.03.20020248. doi:10.1101/2020.02.03.20020248

27. Yau EK, Pang NTP, Shoesmith WD, James S, Hadi NM, Lin LJ. The behaviour changes in response to COVID-19 pandemic within Malaysia. Malaysian Journal of Medical Sciences. 2020;27(2):45-50.

28. Pang NTP, Shoesmith WD, James S, Nor Hadi NM, Yau EK, Lin LJ. Ultra brief psychological interventions for covid-19 pandemic: Introduction of a locallyadapted brief intervention for mental health and psychosocial support service. Malaysian Journal of Medical Sciences. 2020;27(2):51-6. 
29. Pang NTP, Kamu A, Hambali NL, Mun HC, Kassim MA, Mohamed NH, Ayu F, Rahim SS, Omar A, Jeffree MS. Malay Version of the Fear of COVID-19 Scale: Validity and Reliability. International Journal of Mental Health and Addiction. 2020 Jul 3:1-0. 